Abstracta Iranicanica

Revue bibliographique pour le domaine irano-aryen

Volume 32-33 | 2013

Comptes rendus des publications de 2009-2010

\title{
Prods Oktor Skjærvø. On Videvdad Chapter 5.1-13 and its Pahlavi Commentaries
}

\section{Mihaela Timus}

\section{(2) OpenEdition}

1 Journals

\section{Édition électronique}

URL : http://journals.openedition.org/abstractairanica/40125

DOI : 10.4000/abstractairanica.40125

ISSN : 1961-960X

Éditeur :

CNRS (UMR 7528 Mondes iraniens et indiens), Éditions de l'IFRI

\section{Édition imprimée}

Date de publication : 1 décembre 2013

ISSN : 0240-8910

\section{Référence électronique}

Mihaela Timus, "Prods Oktor Skjærvø. On Videvdad Chapter 5. 1-13 and its Pahlavi Commentaries », Abstracta Iranica [En ligne], Volume 32-33 | 2013, document 17, mis en ligne le 01 juillet 2016, consulté le 26 septembre 2020. URL : http://journals.openedition.org/abstractairanica/40125 ; DOI : https:// doi.org/10.4000/abstractairanica.40125

Ce document a été généré automatiquement le 26 septembre 2020.

Tous droits réservés 


\title{
Prods Oktor Skjærvø. On Videvdad Chapter 5.1-13 and its Pahlavi Commentaries
}

\author{
Mihaela Timus
}

\section{RÉFÉRENCE}

«On Videvdad Chapter 5.1-13 and its Pahlavi Commentaries », in : Éric Pirart, Xavier Tremblay, éds., Zarathushtra entre l'Inde et l'Iran. Études iraniennes et indoeuropéennes offertes à Jean Kellens à l'occasion de son $65^{\mathrm{e}}$ anniversaire. Wiesbaden, Ludwig Reichert Verlag, 2009, p. 289-304.

1 L'article porte précisément sur la manière dont l'avestique ərəઈuuō.ånhanəm a été traduit en pehlevi, dans la partie introductive du Videvdad 5 (Vd.). Surtout les paragraphes 10 à 13 portent sur la mesure des huttes (av. kata-), i.e. sur les conditions de construction de ce type de demeure funéraire, employée par les Zoroastriens au temps de l'hiver. Il s'avère qu'elle doit être suffisamment longue et large pour abriter les pieds et les bras du cadavre, suffisamment haute pour que le sommet du crâne ne se heurte pas contre sa surface intérieure.

2 Pour ce qui est du premier terme ərəઈuūo, l'A. dresse le répertoire des traductions occidentales antérieures: "high above » (Cantera), « up above» (Hintze), «à la verticale» (Kellens). Les traducteurs en moyen-perse, quant à eux, ont fait l'équivalence avec stēndag, i.e. "standing », «être debout». Question problématique : l'ambiguïté de l'orthographe du terme pehlevi que l'on peut lire soit stēnig (pourtant non attesté) soit stēndag.

3 Quant au deuxième terme avestique ånhanəm, le problème principal remonte à la double racine āh-, à comprendre comme 1. bouche; ou 2. (être) assis. Pour ce qui est du premier sens, c'est A. W. Jackson (1889) qui en avait fait le choix, en lisant la prescription funéraire du Vd. 5 comme « [la hutte] construite en sorte que la tête, avec 
le visage (litt. la bouche) retourné, ne se heurte pas ». L'A. donne quelques exemples de divergence sémantique pour la même forme åghānō (G) : «bouche » (Vd. 3.29), ou bien «assis » (Pursišnīhā 10). Ce deuxième terme du composé avestique a été rendu par le m.p. zīndag (...) āhan, où àhan est censé traduire l'av. ånhanəm, alors que zīndag figure comme glose. L'A. rejette la correction de Jamasp, qui a lu zinndag $\bar{a}$-šann, en corrigeant inutilement le manuscrit IM.

4 Étant donné que le sens auquel conduit la formule choisie par les traducteurs en pehlevi («être debout vivant ») n'est guère concordant avec le contexte funéraire envisagé, l'A. conclut que l'intelligence correcte de l'av. ərəঠuuō.åghanəm doit être « sitting upright », « assis (tout) droit ».

\section{AUTEURS}

\section{MIHAELA TIMUS}

Institut d'Histoire des Religions, Bucarest 